IP Periodica Polytechnica Civil Engineering

\author{
59(4), pp. 503510,2015 \\ DOI: $10.3311 /$ PPci.7608 \\ Creative Commons Attribution (1) \\ RESEARCH ARTICLE
}

\section{Air Void Distribution of Asphalts Determined by Computed Tomography}

\author{
Éva Lublóy, Dávid Ambrus, Kristóf Kapitány, Árpád Barsi
}

Received 09-07-2014, accepted 06-01-2015

\begin{abstract}
Durability and functionality of hot mix asphalts (HMA) depend on air voids and their characteristics. The air void content of asphalt core samples could be determined by direct and indirect methods. The direct methods are destructive since they determine the air void content by decomposing the mix into its individual components. They are usually accurate but time consuming and use hazardous solvents. Because of the environmental hazards and restrictions associated with the solvents other analysis methods become really important. The computed X-ray tomography $(C T)$ makes it possible to create a complete $3 \mathrm{D}$ image about the whole inner structure without any preparation or chemical fixation of the specimen. This nondestructive structure testing has a great significance at the examination of road pavement structures and could substitute a number of complex laboratory test in a more accurate and robust way. This paper demonstrates the CT method for determining the air void distribution. It shows that the proposed method can determine the air void content very accurately and gives a lot of additional information about other features by showing the distribution of the air void content along any arbitrary axis of the core sample.
\end{abstract}

\section{Keywords}

computed tomography $\cdot C T \cdot$ asphalt $\cdot$ nondestructive testing $\cdot$ air void content

\section{Éva Lublóy}

Department of Construction Materials and Engineering Geology, Budapest University of Technology and Economics, Múegyetem rkp. 3, H-1111 Budapest, Hungary

e-mail: lubeva@web.de

\section{Dávid Ambrus}

Department of Highway and Railway Engineering, Budapest University of Technology and Economics, Múegyetem rkp. 3, H-1111 Budapest, Hungary

\section{Kristóf Kapitány}

Árpád Barsi

Department of Photogrammetry and Geoinformatics, Budapest University of Technology and Economics, Múegyetem rkp. 3, H-1111 Budapest, Hungary

\section{Computed Tomography}

Computed tomography (CT) is one branch of diagnostic radiology. Tomography is a Greek-originated word, meaning slice image. Tomographic images or slices of the specimen are obtained from a large series of two-dimensional X-ray images taken in different direction. These cross-sectional images can be combined into a three-dimensional image of the inside structure of the specimen [1].

Computed tomography applications have not been limited to the fields of medicine [2-7]. CT produces a volume of data that can be manipulated in order to demonstrate various bodily structures, therefore CT is used for nondestructive material analysis as well.

In recent years, CT imaging has been increasingly extended to the structural characterization of asphalt concrete [5, 8, 9], cement concrete [10,11], and rock [12,13]. It can be used to reconstruct the 3D structure of a sample for computer simulation of the performance of the material under various loading and environmental conditions. Meanwhile the sample is still intact and can be used for other nondestructive or destructive macro property tests such as strength or modulus tests. Therefore CT is one of the most effective tools to study the microstructure- macro property relation [9]. In computed tomography X-rays from a well collimated source refers to the cross-sectional imaging of an object from either transmission or reflection data collected by illuminating a slice of the object or patient from many different directions.

The first commercially viable CT scanner was invented by Godfrey N. Hounsfield and Allan M. Cormack, and the first patient brain scan was done in 1971. The modern CT scanners contain two X-ray tubes and scan several slices during a spin around the central axis. The scans and the necessary calculations take only a few minutes to accomplish.

The measurement is based on the radiodensity of materials. Radiodensity refers to the relative inability of X-rays to pass through a particular material. Radiodensity can be quantified according to the Hounsfield scale, a principle which is central to CT applications. On the Hounsfield scale distilled water has a value of 0 Hounsfield units (HU), while air is specified as -1000 
HU. The Hounsfield scale ranges between -1024 and +3071 .

The Hounsfield unit of a three-dimensional pixel is determined according to the following formula (Eq. (1)):

$$
H U=\frac{K \cdot\left(\mu-\mu_{\text {water }}\right)}{\mu_{\text {water }}}
$$

where:

$H U$ Hounsfield unit [-],

$K \quad$ constant of $1000[-]$,

$\mu \quad$ linear attenuation coefficient of the particular material $[1 / \mathrm{m}]$,

$\mu_{\text {water }}$ linear attenuation coefficient of distilled water $[1 / \mathrm{m}]$.

\section{CT Application for Testing Asphalt}

Asphalt mixture is a heterogeneous composite material comprised of coarse and fine aggregates, bitumen and voids. Aggregates usually take up about $85 \%$ of the volume of asphalt mixture and usually have different sizes, irregular shapes and random locations. While bitumen is a typical viscous material and its mechanical performances are very sensitive to the temperature. Numerous researches [14-17] proved that mechanical properties of the asphalt mixture are significantly affected by the microstructure and some material parameters including bitumen content, void content and gradation of aggregate particles. Several studies analyzed the inner structure of the aggregate and the asphalt mixture, however CT scanning is not commonly used for testing asphalt material. The few studies based on CT images typically dealt with certain special problems such as permeability, frost-resistance or void structure. However these CT examinations were based only on imagery, without comparison to laboratory tests.

In asphalt mixes, particle shape significantly influences the initial compaction and subsequent performance [18, 19]. Bessa, Castelo Branco and Soares [20] studied the inner structure and grain shape of different aggregates and gradations. The goal of the research was the determination of contact points, segregation potential and grain orientation, which is very difficult by traditional methods. The research showed that digital image processing methods gave more complex and robust results than traditional laboratory tests [21-23].

The examination of permeability of asphalt pavements has been a great challenge for a long time. Moisture damage in asphalt decreases the stiffness and strength of the mixture which ultimately leads to failure of asphalt pavements. Moisture damage affects the performance and durability of asphalt mixtures due to a loss of cohesion in the binder or failure of adhesion between binder and aggregate, and ultimately this affects the structural performance of the mixture [24-26]. Al-Omari et al. [27] were the first to prove the correlation between the permeability estimated based on CT images and the laboratory tests. Gruber et al. [28] made similar research, they examined the void structure and permeability of porous asphalts by superimposing the numeric simulation of flow over the three-dimensional microstructure. The research showed that there was no correlation between permeability and porosity, and flow inside the void structure is strongly anisotropic.

\section{Research Methodology}

In this research core samples of asphalt road pavements were examined by usual laboratory methods and by CT. The void content significantly influences the durability and the performance of pavement structures. The goal of the research was to determine the air void content and distribution of these core samples by both methods and to compare the results. The research investigated if the air void content and distribution could be determined accurately in a nondestructive way.

Three core samples were examined in this research. The core samples were taken from reinforced sections of asphalt road pavements. In case of two samples the upper $2 \mathrm{~cm}$ of the original asphalt pavement was removed and two new asphalt courses were built for reinforcement. At the third sample the original asphalt courses were fully removed to the top of the base course and three new asphalt courses were laid. The core samples contain the new and the original pavement courses to the base course.

The evaluation of the CT scanning was based on the Hounsfield units and image analysis.

The research hypotheses were the following:

- CT images are suitable to determine the border of asphalt courses,

- CT images make possible to analyze the structure, air void content and distrubution of the courses in detail.

\section{Laboratory Tests}

The core samples were cut at the borders of the courses. The width of cutting blade was $14 \mathrm{~mm}$, so $7 \mathrm{~mm}$ of material were lost at both sides of the borders. This loss of material was important from the point of view of air void content, because the CT images showed that the bulk density of asphalt is lower at the borders of courses.

The air void contents of the courses were determined by solvent extraction method according to the European standards. After cutting the bulk densities of courses were determined. Then the courses were extracted by solvent, and the density was measured again, now without the voids. Based on these two values the mean air void contents of the courses were determined according to the following formula (Eq. (2)):

$$
V_{m}=\left(1-\frac{\rho_{t S S D}}{\rho_{m v}}\right) \cdot 100
$$

where:

$V_{m} \quad$ air void content,

$\rho_{t S S D}$ bulk density with voids,

$\rho_{m v} \quad$ density without voids. 
Tab. 1. Results of Laboratory Tests for Determining Air Void Content

\begin{tabular}{|c|c|c|c|}
\hline Sample identifier & Type of course & Course thickness & Air void content \\
\hline \multirow{3}{*}{ Sample Nr. 3} & AC 16 wearing $(F)$ & $42 \mathrm{~mm}$ & $5.1 \%$ \\
\hline & AC 22 binding $(F)$ & $75 \mathrm{~mm}$ & $5.7 \%$ \\
\hline & AC 22 base $(F)$ & $78 \mathrm{~mm}$ & $5.7 \%$ \\
\hline \multirow{2}{*}{ Sample Nr. 5} & AC 16 wearing $(F)$ & $72 \mathrm{~mm}$ & $5.0 \%$ \\
\hline & AC 32 base $(F)$ & $88 \mathrm{~mm}$ & $5.9 \%$ \\
\hline \multirow{2}{*}{ Sample Nr. 9} & AC 16 wearing $(F)$ & $60 \mathrm{~mm}$ & $3.8 \%$ \\
\hline & AC 32 binding $(F)$ & $94 \mathrm{~mm}$ & $3.9 \%$ \\
\hline
\end{tabular}

The results of the laboratory tests for determining air void content are summarized in Table 1

\section{Testing by Computed Tomography}

The CT tests were made by a Siemens Somatom 16 device at the Diagnostic and Oncoradiology Institute of Kaposvar University in Hungary. The thickness of slices was $1.2 \mathrm{~mm}$ and the pixel spacing was $0.39 \mathrm{~mm}$. The CT slices were processed by automated algorithms in Matlab environment using predefined parameters without any user interaction. The segmentation of aggregates, air voids and binding materials was performed with thresholding [29], but additional filters and corrections were necessary to reduce noise and beam hardening [30,31] effects. The method is using Fast Fourier Transformation [32] to detect dense structures (e.g. aggregates) inside rare materials (e.g. binding mortar). The algorithms process the CT slices successively one at a time. The result of the process are tabular formed statistics (per slice and globally) and segmented images as well.

The aggregate particles, the bitumen-mortar and the air voids separate clear on the CT images (Fig. 11). The aggregate and pores distribution can be given in 3D (Fig. 2).

The volume percent of aggregate, bitumen mortar and pores are demonstrated in Fig. 3. The high or low values from aggregate or bitumen mortar content could be explained with the structure of asphalt. The courses of the core samples could be identified on the CT images, the borders of the courses could be determined with $\mathrm{mm}$ accuracy by the air void distribution. It could be seen in Fig. 3 that the air void content changes dramatically at the borders of courses. This fact makes it possible to distinguish the courses from each other and to conduct distinct analysis by courses.

After the CT image processing the distribution of the air void content and distribution along the slices was determined. Results are shown along the vertical axis of the core sample (Fig. 4 Fig. 5). The air void content changes at the borders significantly and visibly. The aggregate distribution is not homogenous inside the courses. The fluctuation of aggregate and air void content inside the courses could be explained by compaction problems.

In Fig. 6 are demonstrated the air void distributions in all courses. The air void distribution in the courses 2 and 3 are similar, in the course 1 the diameters of air void are bigger as in the courses 2 and 3 .

The air void content were determined as the average value of slices taken along the vertical axis of the core sample. Table 2 summarizes the results. It should be noted, that the air void contents and distribution at the borders differ significantly from the ones inside the courses.

Sample Nr. 5 (Fig. 3) shows some interesting features. After milling the original wearing course became thinner than $1 \mathrm{~cm}$. The air void starts to change at the border, and this change is continuous to air void content of the original wearing course. There is no abrupt changes of air void as at the other borders of courses. This fact may imply the good connection between the courses. Consequently the determination of the borders between courses of similar densities may be difficult in case of good connection; the border will be less evident.

At this sample the air void content increases abruptly inside the original binding course. Its reason is worth to analyze in further researches, it is probably caused by inadequate spreading and compaction.

\section{Comparison of the Results of Laboratory and CT Tests}

Table 3 compares the air void contents measured in laboratory or calculated from CT tests. The results show minimal differences, so the proposed CT method is as accurate as the direct methods for determining the air void content. For calibrating the method the cutting sections of the laboratory method were identified on the CT slices, and the air void content was determined by omitting these slices. Based on the results the proposed method is accurate and could be used as a substitute for the standard laboratory methods.

Based on the distribution of air void contents it could be stated that the location of cutting significantly affects the measured and the calculated air void content. Thus at the laboratory methods the precise cutting is very important. The CT method can handle this problem easily, the air void content of the cutting width can be taken into account as well. But the significantly different values of the cutting width affect the results. It should be noted here that the CT methods could be easily fitted to the laboratory test by omitting the values of the cutting width.

The results of CT analysis also show that more accurate results can be obtained by CT than by laboratory tests. In the contact zones between different asphalt courses the air void content is significantly higher. The CT method shows the distribution of air void content values along the vertical axis of the core sample. 


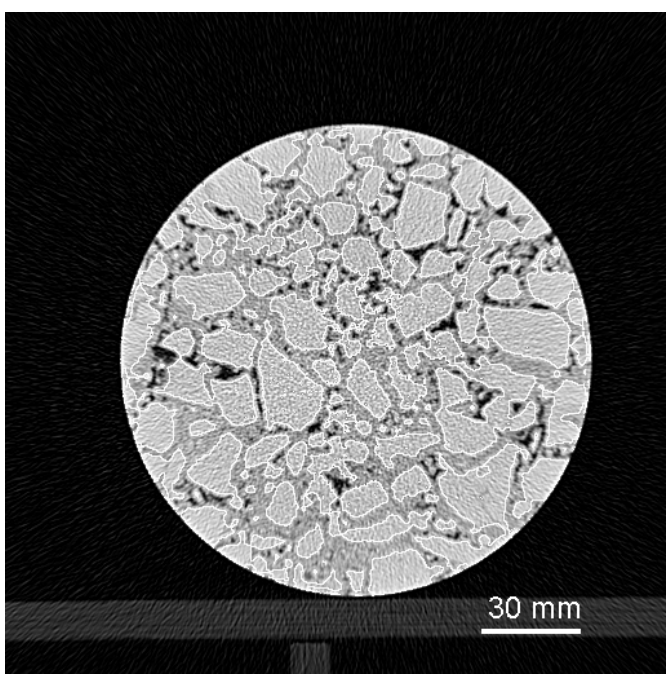

(a)

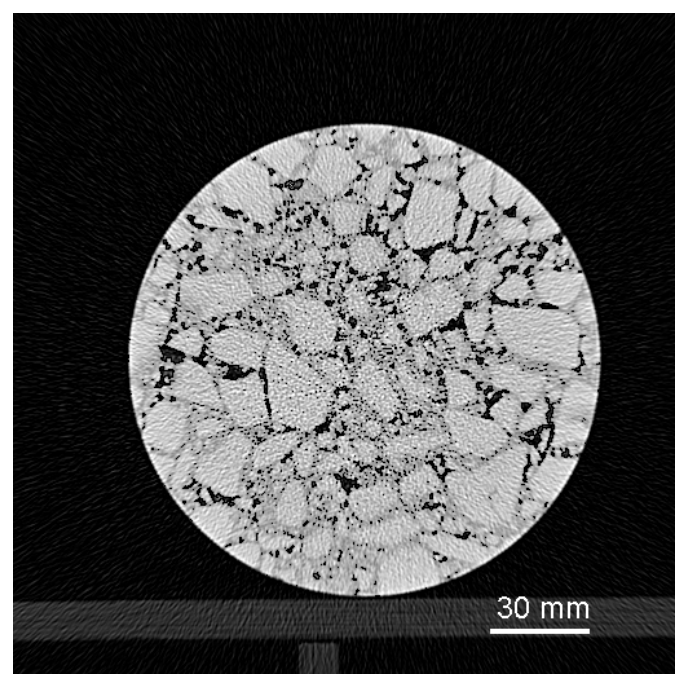

(b)

Fig. 1. The aggregates outlined with white (a), and the air voids outlined with black (b) on a cross section

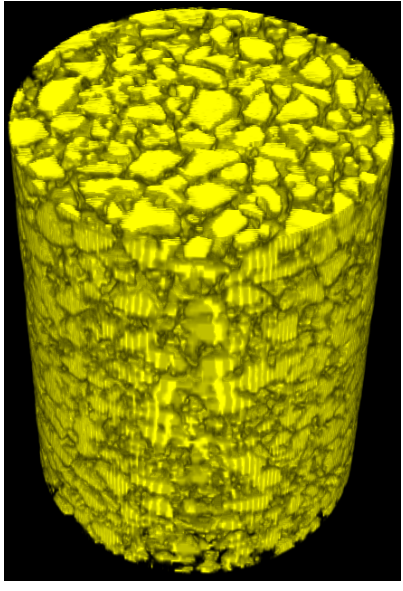

(a)

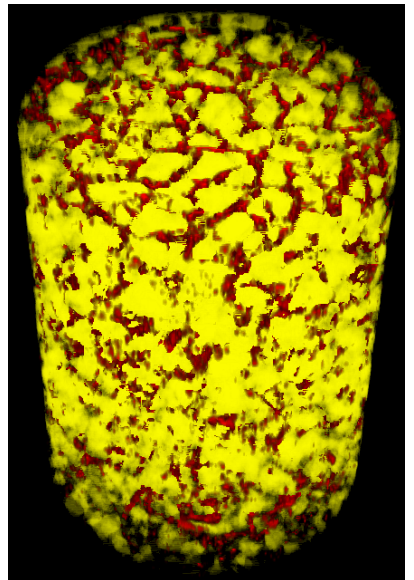

(b)

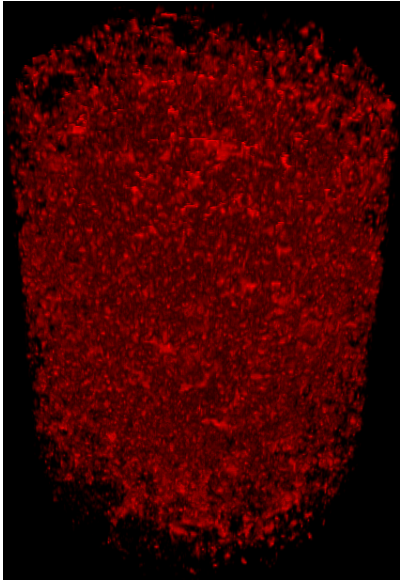

(c)

Fig. 2. The 3D image of aggregates (a) and pores (c) distribution, as well as their superimposing (b) in ImageJ software

Tab. 2. Results of CT Tests for Determining Air Void Content

\begin{tabular}{cccc}
\hline Sample identifier & Type of course & Course thickness & Air void content \\
\hline \multirow{2}{*}{ Sample Nr. 3 } & AC 16 wearing (F) & $29 \mathrm{~mm}$ & $5.3 \%$ \\
& AC 22 binding (F) & $82 \mathrm{~mm}$ & $5.2 \%$ \\
& AC 22 base (F) & $73 \mathrm{~mm}$ & $4.9 \%$ \\
\hline \multirow{2}{*}{ Sample Nr. 5 } & AC 16 wearing (F) & $150 \mathrm{~mm}$ & $4.5 \%$ \\
& AC 32 base (F) & $66 \mathrm{~mm}$ & $4.4 \%$ \\
\hline \multirow{2}{*}{ Sample Nr. 9 } & AC 16 wearing (F) & $59 \mathrm{~mm}$ & $3.9 \%$ \\
& AC 32 binding (F) & $84 \mathrm{~mm}$ & $5.5 \%$ \\
\hline
\end{tabular}




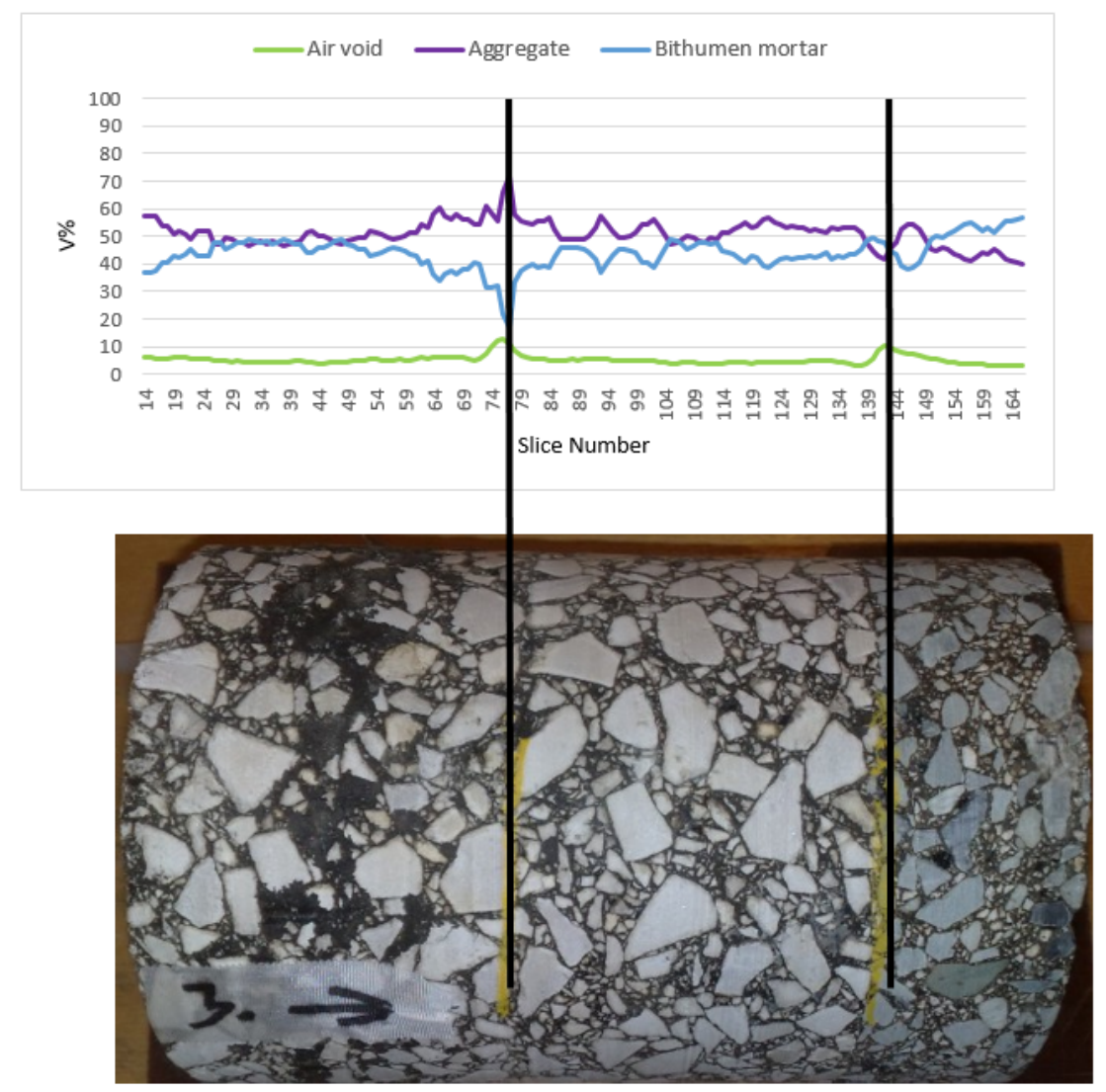

Fig. 3. Borders between courses

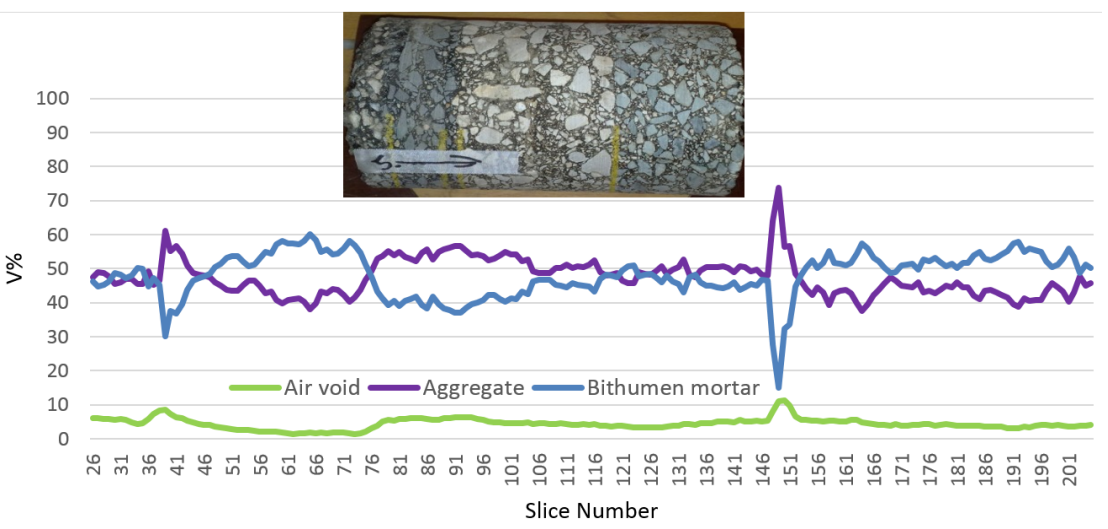

Fig. 4. Sample Nr. 5: Distribution of aggregates, bithumen mortar and air void contents along the vertical axis

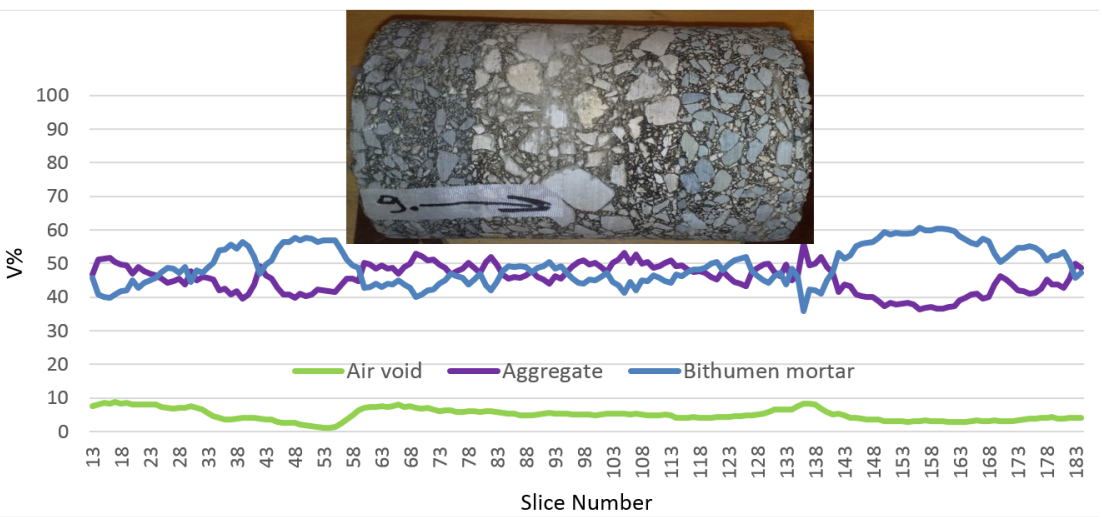

Fig. 5. Sample Nr. 9: Distribution of aggregates, bithumen mortar and air void contents along the vertical axis 

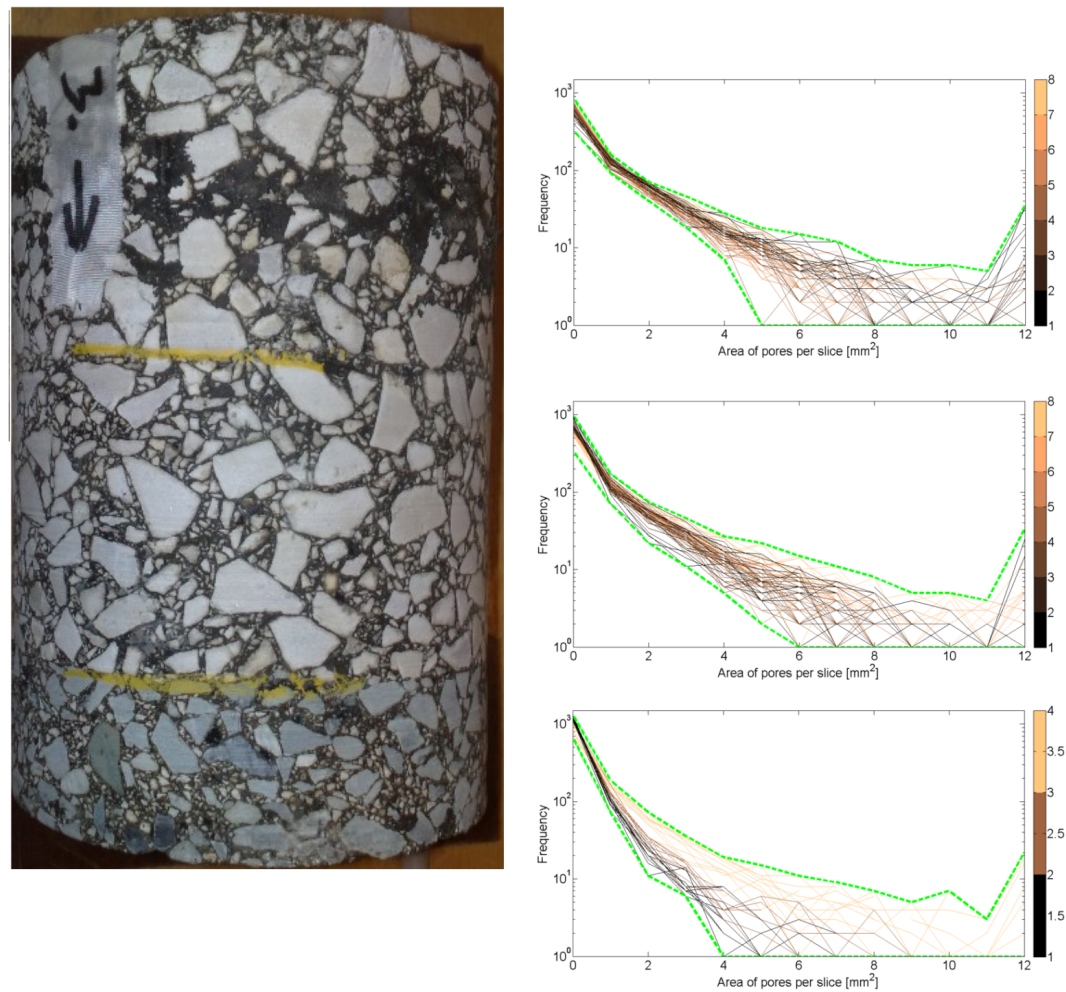

Fig. 6. Sample Nr. 3: Distribution of air void in all courses. It shows the frequency of pores with different area size (in $\mathrm{mm}^{2}$ ) in each CT image on a semi

logarithmic scale. The colorbar shows the vertical location of the cross-section.

The air void content is not homogenous even inside the courses, which may be explained by the compaction.

The CT method can show if the surface of the road was uneven before laying the course. In this case the air void content changes along a wider interval (Fig. 3).

\section{Conclusions}

A lot of useful information could be gained about the structural features of road pavements by CT based method. The air void content on the rand of courses were significantly different, so the method can distinguish the courses and is suitable for the analysis of the characteristics of pavement structures by courses. On the CT images the aggregate particles, the bitumen mortar and the air voids separates well, so the method is suitable for other structural analysis, such as the determination of bitumen mortar content.

The air void content significantly influences the durability and the performance of pavement structures. The goal of the research was to determine the air void content of these core samples by both methods and to compare the results. The research investigated if the air void content could be determined accurately in a nondestructive way.

Three core samples taken from reinforced sections of asphalt roads were examined in the research. The evaluation of the CT scanning was based on image analysis. The CT slices were processed by automated algorithms in Matlab environment using predefined parameters without any user interaction. The segmentation of aggregates, air voids and binding materials was performed with thresholding. The algorithms process the CT

slices successively one at a time. The result of the process are tabular formed statistics (per slice and globally) and segmented images as well.

The research has proven the two hypotheses regarding the suitability for asphalt intercourse border determination and the possibility to analyze the sample structure.

The CT and the laboratory tests gave the same result, which rise the question, whether the CT technology can replace the time and cost-consuming laboratory method. The more environment respect of the CT method is also advantageous in contrast to the standard laboratory tests.

The results of CT analysis also show that more accurate results can be obtained by CT than by laboratory tests. In the contact zones between different asphalt courses the air void content is significantly higher. The CT method displays that the air void content is not homogenous even inside the courses, which may be explained by the compaction. The CT method exposes the building problems and inhomogeneities as well.

The analyses based on CT tests have a lot of additional advantages, further application possibilities. The CT method is able to show the constructional problems and inhomogeneity (that has a great impact to frost-resistance and durability), to give information about the extent of cooperation between courses. The structural analyses made by CT give not only one value but a distribution of values, so the characteristics of any given part could be examined, which has a great methodological advance at structural analyses.

The proposed CT method is therefore suitable to examine the 
Tab. 3. Comparison of Results of Laboratory and of CT Tests

\begin{tabular}{cccc}
\hline Sample identifier & $\begin{array}{c}\text { Air void content, } \\
\text { laboratory }\end{array}$ & Air void content, CT & Difference \\
\hline \multirow{2}{*}{ Sample Nr. 3 } & $5.1 \%$ & $4.9 \%$ & $4 \%$ \\
& $5.7 \%$ & $5.2 \%$ & $9 \%$ \\
& $5.7 \%$ & $5.3 \%$ & $7 \%$ \\
\hline \multirow{2}{*}{ Sample Nr. 5 } & $5.0 \%$ & $4.5 \%$ & $10 \%$ \\
& $5.9 \%$ & $4.4 \%$ & $25 \%$ \\
\hline \multirow{2}{*}{ Sample Nr. 9 } & $3.8 \%$ & $3.9 \%$ & $3 \%$ \\
& $3.9 \%$ & $5.5 \%$ & $38 \%$ \\
\hline
\end{tabular}

structural characteristics of asphalt mixtures and road pavements with great accuracy, and the method is promising for innovative future implementation possibilities.

\section{References}

1 Hounsfield GN, Computerized transverse axial scanning (tomography): Part 1. Description of system, The British Journal of Radiology, 46(552), (1973), 1016-1022, DOI 10.1259/0007-1285-46-552-1016

2 Petrovic AM, Siebert JE, Rieke PE, Soil Bulk Density Analysis in Three Dimensions by Computed Tomographic Scanning, Soil Science Society of America Journal, 46(3), (1982), 445-450, DOI 10.2136/sssaj1982.03615995004600030001x

3 Aylmore LAG, Hainsworth JM, The use of computer assisted tomography to determine spatial distribution of soil water content, Australian Journal of Soil Research, 21(4), (1983), 435-443, DOI 10.1071/SR9830435

4 Aylmore LAG, Hainsworth JM, Water extraction by single plant roots, Soil Science Society of America Journal, 50(4), (1986), 841-848, DOI 10.2136/sssaj1986.03615995005000040003x

5 Braz D, da Motta LMG, Lopes RT, Computed tomography in the fatigue test analysis of an asphaltic mixture, Applied Radiation and Isotopes, 50(4), (1999), 661-671, DOI 10.1016/S0969-8043(98)00122-5

6 Braz D, Lopes RT, da Motta LMG, Analysis of the percentage voids of test and field specimens using computerized tomography, Nuclear Instruments and Methods in Physics Research Section A: Accelerators, Spectrometers, Detectors and Associated Equipment, 422(1-3), (1999), 942-948, DOI 10.1016/S0168-9002(98)01051-1

7 Braz D, Lopes RT, da Motta LMG, Research on fatigue cracking growth parameters in asphaltic mixtures using computed tomography, Nuclear Instruments and Methods in Physics Research Section B: Beam Interactions with Materials and Atoms, 213, (2004), 498-502, DOI 10.1016/S0168583X(03)01610-0

8 Shashidhar N, X-ray tomography of asphalt concrete, Transportation Research Record: Journal of the Transportation Research Board, 1681, (1999), 186-192, DOI 10.3141/1681-22

9 Wang LB, Frost JD, Shashidhar N, Microstructure Study of WesTrack Mixes from X-Ray Tomography Images, Transportation Research Record: Journal of the Transportation Research Board, 1767, (2001), 85-94, DOI 10.3141/1767-11

10 Landis EN, Denis KT, X-ray microtomography for fracture studies in cement-based materials, Proceedings of SPIE, The International Society for Optical Engineering, 3772, (1999), 105-113.

11 Hall C, Colston SL, Jupe AC, Jacques SDM, Livingston R, Ramadan AOA, Amde AW, Barnes P, Non-destructive tomographic energydispersive diffraction imaging of the interior of bulk concrete, Cement and Concrete Research, 30(3), (2000), 491-495, DOI 10.1016/S00088846(00)00206-4

12 Berényi E, Bogner P, Horváth G, Repa I, Radiológia, Springer Hungarica, 1997.
13 Radaelli F, Balzarini M, Nicula S, Ortenzi A, Rock structure characterization through imaging techniques integration, Proceedings of the European Petroleum Conference, 1, (1998), 23-25.

14 Airey GD, Hunter AE, Collop AC, The effect of asphalt mixture gradation and compaction energy on aggregate degradation, Construction and Building Materials, 22(5), (2008), 972-980, DOI 10.1016/j.conbuildmat.2006.11.022

15 Liu QQ, Cao DW, Research on Material Composition and Performance of Porous Asphalt Pavement, Journal of Materials in Civil Engineering, 21(4), (2009), 135-140, DOI 10.1061/(ASCE)0899-1561(2009)21:4(135)

16 Shen DH, Kuo MF, Du JC, Properties of gap-aggregate gradation asphalt mixture and permanent deformation, Construction and Building Materials, 19(2), (2005), 147-153, DOI 10.1016/j.conbuildmat.2004.05.005

17 Yin A, Yang X, Yang S, Jiang W, Multiscale fracture simulation of three-point bending asphalt mixture beam considering material heterogeneity, Engineering Fracture Mechanics, 78(12), (2011), 2414-2428, DOI 10.1016/j.engfracmech.2011.06.001

18 Monismith C, Influence of shape, size, and surface texture on the stiffness and fatigue response of asphalt mixtures, Highway Research Board Special Report, 109, (1970), 4-11.

19 Masad E, Olcott D, White T, Tashman L, Correlation of fine aggregate imaging shape indices with asphalt mixture performance, Transportation Research Record: Journal of the Transportation Research Board, 1757, (2001), 48-156, DOI 10.3141/1757-17

20 Bessa IS, Castelo Branco VTF, Soares JB, Evaluation of different digital image processing software for aggregates and hot mix asphalt characterizations, Construction and Building Materials, 37, (2012), 370-378, DOI 10.1016/j.conbuildmat.2012.07.051

21 Barksdale R, Itani S, Influence of aggregate shape on base behavior, Transportation Research Record: Journal of the Transportation Research Board, 1227, (1994), 171-182.

22 Rao C, Tutumluer E, Kim IT, Quantification of Coarse Aggregate Angularity Based on Image Analysis, Transportation Research Record: Journal of the Transportation Research Board, 1787, (2002), 117-124, DOI 10.3141/178713

23 Coleri E, Harvey JT, Yang K, Boone JM, A micromechanical approach to investigate asphalt concrete rutting mechanisms, Construction and Building Materials, 30, (2012), 36-49, DOI 10.1016/j.conbuildmat.2011.11.041

24 Collop AC, Choi YK, Airey GD, Effect of pressure and ageing in SATS test, ASCE Journal of Transportation Engineering, 133(11), (2007), 619-624, DOI 10.1061/(ASCE)0733-947X(2007)133:11(618)

25 Collop AC, Choi YK, Airey GD, Elliot RC, Development of the saturation aging tensile stiffness (SATS) test, Proceedings of the Institution of Civil Engineers - Transport, 157(3), (2004), 163-171, DOI 10.1680/tran.157.3.163.41184

26 Khan R, Grenfell J, Collop A, Airey G, Gregory H, Moisture damage in asphalt mixtures using the modified SATS test and image analysis, Construction and Building Materials, 43, (2013), 165-173, DOI 10.1016/j.conbuildmat.2013.02.003 
27 Al-Omari A, Tashman L, Masad E, Cooley A, Harman T, Proposed methodology for predicting HMA permeability, Journal of the Association of Asphalt Paving Technologists, 71, (2002), 30-58.

28 Gruber I, Zinovik I, Holzer L, Flisch A, Poulikakos LD, A computational study of the effect of structural anisotropy of porous asphalt on hydraulic conductivity, Construction and Building Materials, 36, (2012), 66-77, DOI 10.1016/j.conbuildmat.2012.04.094

29 Russ JC, Image Processing Handbook, 6th edn., CRC Press, 2011.

30 Buzug TM, Computed Tomography - From Photon Statistics to Modern Cone-Beam CT, Springer-Verlag, 2008.

31 Van de Casteele E, Model-based approach for Beam Hardening Correction and Resolution Measurements in Microtomography, $\mathrm{PhD}$ thesis, University of Antwerp, 2004.

32 Oppenheim AV, Schafer RW, Buck JR, Discrete-time signal processing, Prentice Hall, Inc., 1999. 